\title{
REFLEXIONES SOBRE LA DECORACION DE UN VASO MAYA
}

\section{Por Marta Foncerrada de Molina}

El Museo de Arte Primitivo de Nueva York adquirió recientemente un hermoso vaso maya, cuya decoración artística y tentativo análisis iconográfico son el tema del presente artículo. El vaso aparece descrito en la cédula del Museo como "vasija cilíndrica de barro pintado, perteneciente a la cultura maya de México (ca. 700 d.C.) y decorado con una escena mitológica que parece ser la representación del viaje nocturno del sol por el inframundo". Las medidas aproximadas del vaso son 14 centímetros de altura por 11 centímetros de diámetro.

La pieza es de gran calidad artística tanto por el diseño que decora esta vasija, de elegante y sobria sencillez, como por la originalidad y fuerza expresiva de la composición pictórica que muestra una interesante y compleja sucesión de imágenes, entre las que se insertó un texto jeroglifico que incluye numerales y glifos calendáricos. Estos últimos dan una fecha de rueda calendárica, 7 Muluc, 7 Kayab, demasiado vaga para fijarla en un periodo determinado. " Sin embargo el estilo pictórico de los glifos, el tipo de composición y la fluidez del dibujo indican que la pieza pertenece al clásico tardío maya, al periodo cerámico designado como fase Tepeu, que abarca un lapso aproximado de 751 a 810 d.C.

La decoración del vaso describe un acontecimiento mítico en el que intervienen varios seres del mundo sobrenatural y la figura de un hombre joven. Este tipo de decoración coloca al vaso en un contexto distinto al de otras piezas de cerámica decorada con escenas de carácter narrativo las que, por lo general, ilustran aspectos de la vida social y ceremonial de los dignatarios mayas.

Efectivamente, como lo asienta la cédula del Museo de Arte Primitivo de Nueva York, la escena parece aludir al viaje nocturno del sol por el inframundo; lo anterior sin embargo no se refiere sino a una parte del relato mitico, pues aparecen otros elementos iconográficos importantes que merecen un detenido estudio. En el presente trabajo me ocuparé principalmente del análisis de la figura de hombre joven, ilustrada en la figura 1.

- Agradezco profundamente al doctor Henrich Berlin el haberse ocupado del análisis de estos gífos calendáricos. 
En el dibujo extendido aparecen 6 imágenes (fig. 4). De izquierda a derecha, la primera es la de un personaje joven que sale de las fauces de un monstruo serpentino, que es la segunda imagen; este último está representado no en forma naturalista sino como una variante más del modo en que los mayas caracterizaron los dragones, tanto celestes como del inframundo; en este caso es símbolo del dios que vive en el reino de las tinieblas y de la muerte.

La tercera imagen (fig. 2), es la representación antropozoomorfa del dios del sol, el que aparece en posición horizontal, recostado en la serpiente; el rostro del dios solar es el típico de la iconografía del periodo clásico, la variante que lo singulariza, y que tiene interés particular, es la posición que adopta y el que se le represente con manos, pies, orejas y cola de jaguar, elementos que indican su transformación en sol nocturno, uno de cuyos símbolos es el jaguar.

La cuarta imagen es la del dios de la muerte, cuyos brazos y manos descarnados se abren para recibir en el inframundo al sol que empieza a transformarse en jaguar. La figura posee gran movimiento, el esqueleto parece ejecutar una danza. En la composición pictórica se advierte que el artista maya quiso contraponer la figura del personaje joven con la del dios de la muerte, símbolo el uno de la vida y la luz y el otro del inframundo y las tinieblas (fig. 3).

La quinta imagen (fig. 4) es la de un perro de fiero aspecto con patas y cola de jaguar y largas y colgantes orejas que ostentan las características manchas de la piel de este animal; se trata seguramente del perro mítico que acompaña al sol por las regiones del oscuro inframundo y de ahí le vienen los rasgos felinos.

Un estandarte o posible adorno posterior del dios de la muerte adornado con símbolos de muerte, como son los huesos y cascabeles, forma un eje diagonal muy acentuado que separa al perro mítico de la imagen danzarina del dios de la muerte.

Finalmente, completa la composición la sexta imagen: un extraño y pequeño ser que posee las características de un insecto antropozoomorfo ya que se le representó con manos, una de las cuales coge una antorcha (fig. 4). En la frente ostenta el signo del día "Akbal, simbolo calendárico relacionado con las tinieblas, el inframundo, el jaguar y el sol nocturno", ${ }^{1}$ lo que parece confirmarse con los 3 cascabeles $u$ ojos de muerte que rodean su cabeza. El insecto posee ciertos rasgos anató-

1 León-Portilla, 1968, p. 50. 
DOI: http://dx.doi.org/10.22201/iie.18703062e.1970.39.915

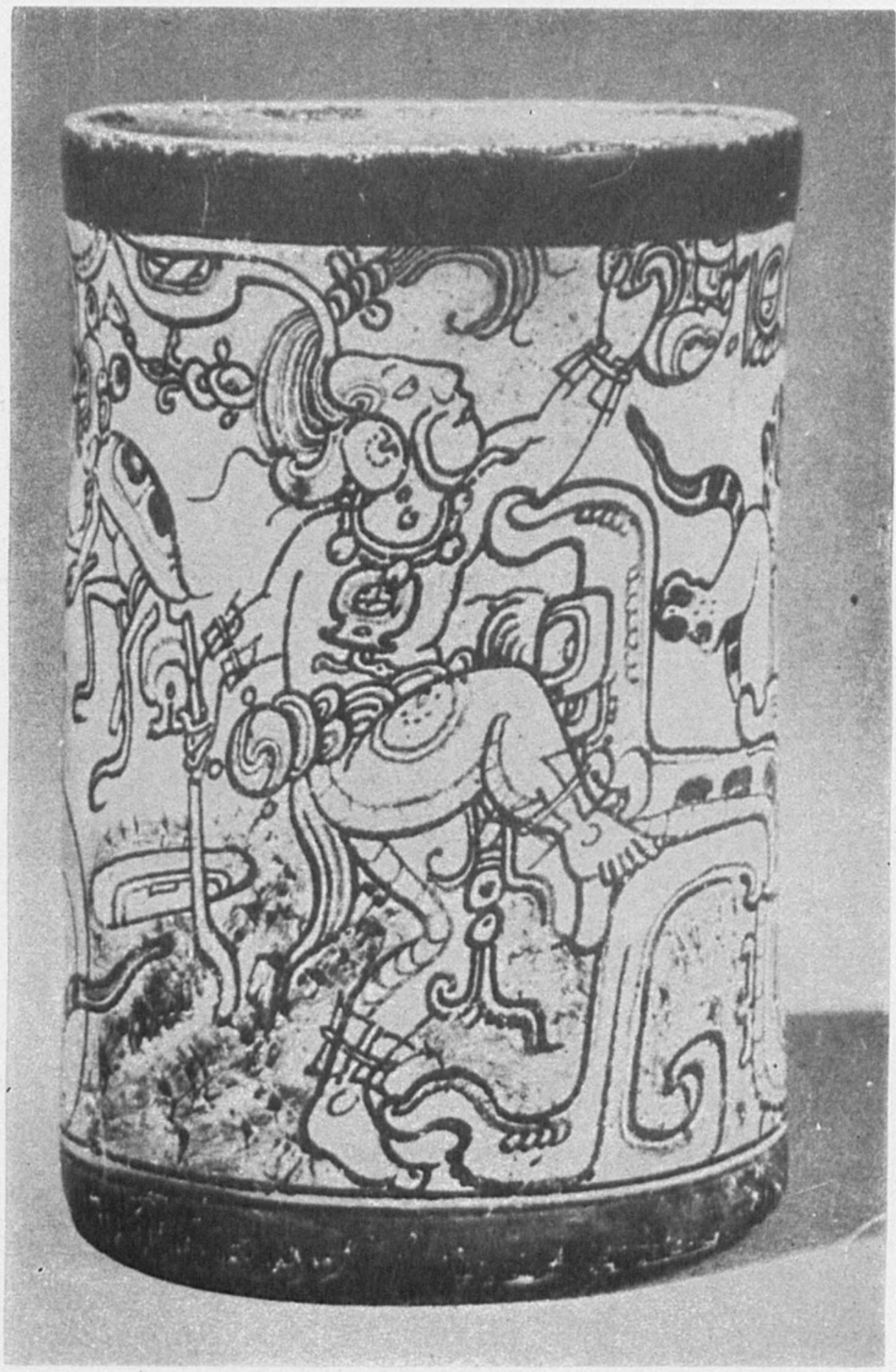

1. Personaje joven 
DOI: http://dx.doi.org/10.22201/iie.18703062e.1970.39.915

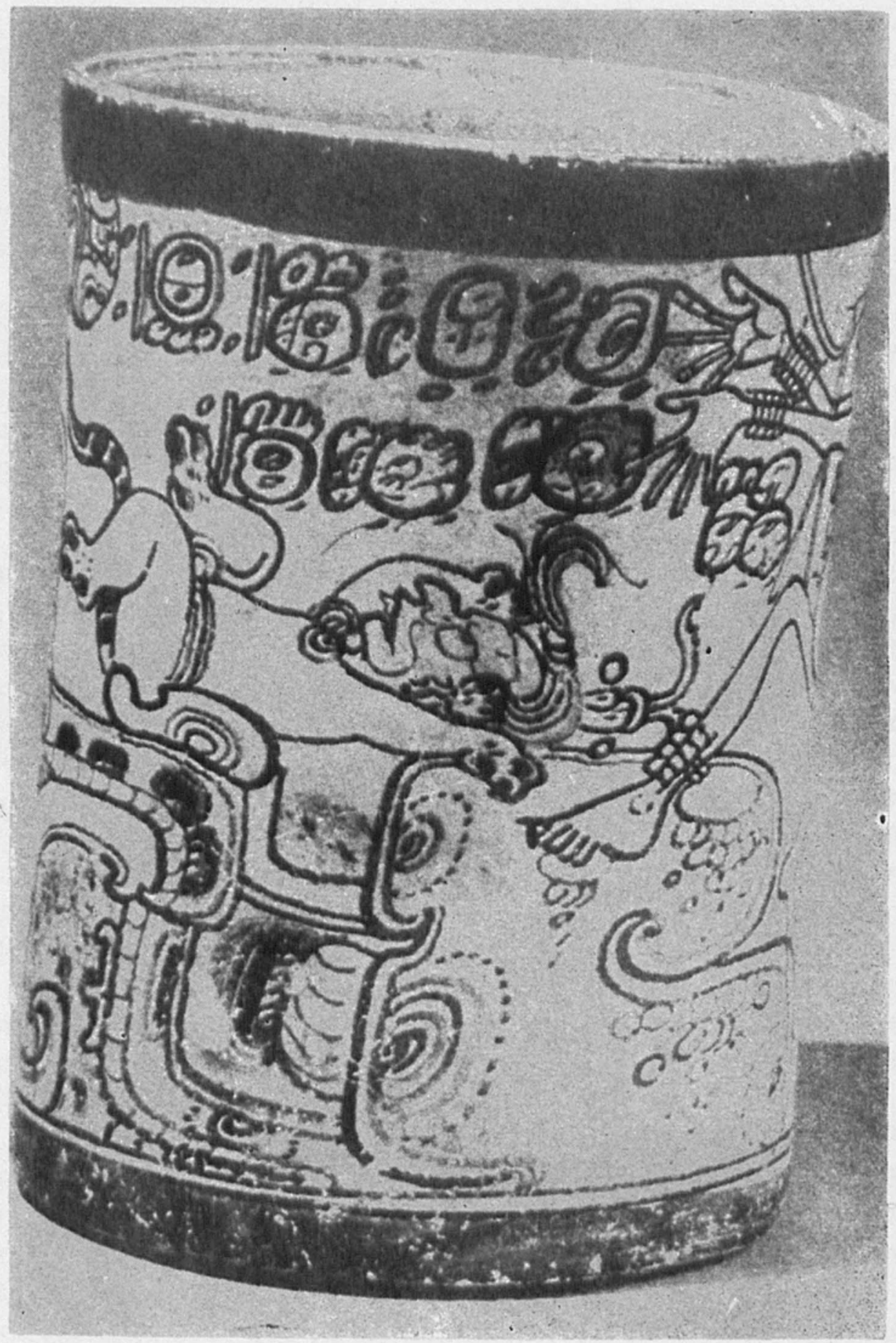

2. Dios del sol 
DOI: http://dx.doi.org/10.22201/iie.18703062e.1970.39.915

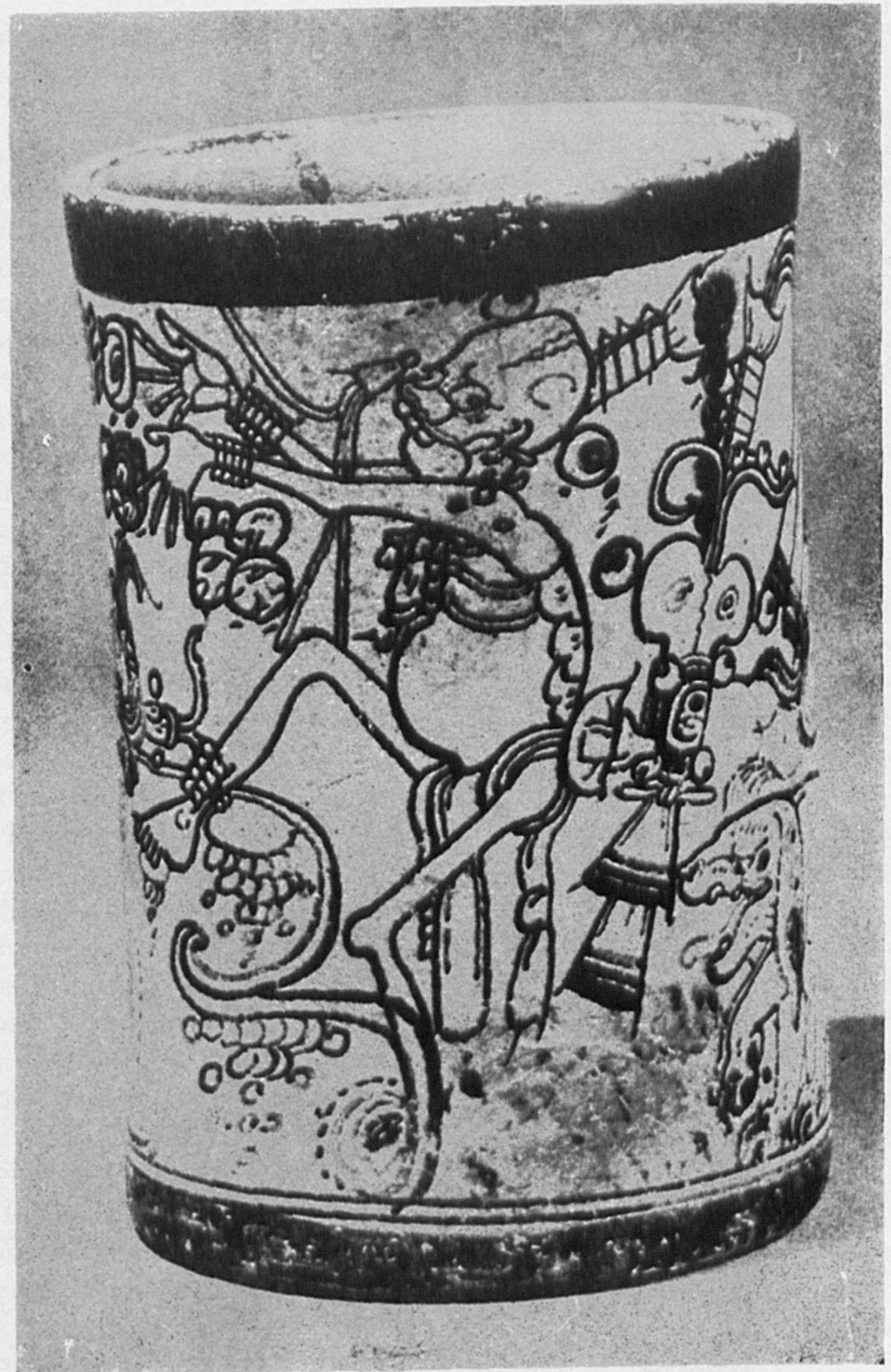

3. Dios de la muerte 


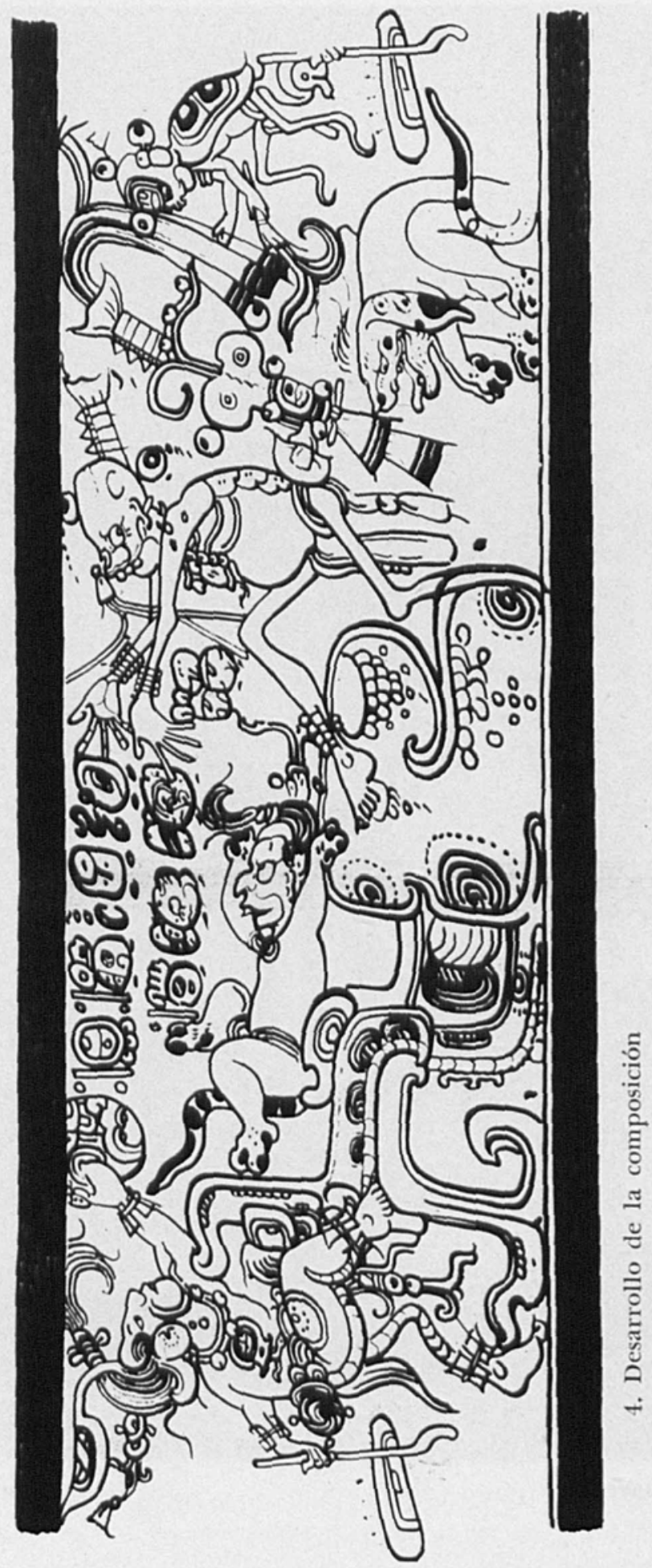


micos que pudieran indicar que se trata de una abeja, animal que para los mayas de Yucatán fue símbolo del alma de los muertos.

La decoración del vaso se realizó sobre un fondo amarillo cremoso que es el color del engobe sobre el que se pintaron 2 bandas, una superior y otra inferior de color rojo quemado. El diseño es un hermoso dibujo a pincel en el que la línea de color sepia es el recurso plástico que el artista maya escogió para realizar la composición. Se advierte un trazo directo, sin titubeos ni rectificaciones, ejecutado por la mano maestra de un extraordinario dibujante. La línea en ocasiones es muy fina y en otras se engruesa para perfilar y caracterizar, sin colorear, las imágenes, ni los demás elementos que integran el diseño decorativo. La pieza está extraordinariamente bien conservada y nos permite seguir sin dificultad el complejo movimiento de la línea, la que, rehuyendo los ángulos rectos y los perfiles angulosos, se desliza ondulante a todo lo largo de la superficie pictórica.

Al comparar este hermoso vaso maya con otros de semejante calidad artística, observo que en éste existe un mayor abarrocamiento de las formas, tanto en la línea como en la composición. El movimiento ondu. lante de la línea, la repetición de ejes diagonales en las formas, la intima relación de las imágenes entre sí, que deja pocos espacios libres, justifican mi aseveración anterior.

El artista maya resolvió con imaginación y libertad creativa los problemas de organización formal que le planteaba la decoración del vaso y estableció una armoniosa sucesión de imágenes, en las que puede advertirse un plano superior y otro inferior marcados por un eje horizontal ideal constituido por la línea superior del monstruo de la tierra y el lomo del perro mítico. Por otra parte, observo en el dibujo extendido un sutil sentido de la perspectiva logrado por la modulación de la línea, el movimiento alterno de ejes y la dinámica posición de las imágenes, lo que produce un efecto visual que capta dos planos, uno anterior y otro que precede.

Como mencioné en párrafos anteriores, en el presente trabajo me ocuparé del análisis iconográfico y la ubicación estilfstica de la dinámica figura del personaje que emerge de las fauces del monstruo de la tierra. La agilidad y libertad de movimientos con que fue representada esta juvenil figura, sugiere que danza alegremente al salir de la región de las tinieblas; el brazo derecho se extiende para coger, a manera de sonaja, una máscara dibujada en el límite superior de la composición, lo que parece indicar que asciende a la región celeste. 
El rostro de perfil, el torso de frente, el movimiento de brazos y piernas representados también de perfil, el interés del artista por impedir que la indumentaria y los adornos oculten los rasgos anatómicos del personaje, indican que el vaso corresponde estilísticamente a la fase dinámica, según la clasificación de Tatiana Proskouriakoff para la escultura del periodo clásico maya, ${ }^{2}$ y a la fase tardía del periodo naturalista dinámico de la escultura en Palenque, ${ }^{3}$ etapas que corresponden aproximadamente a un periodo que va de 751 a 810 d.C.

Las similitudes estilísticas de los periodos escultóricos mencionados en el párrafo anterior corresponden a las características de la pintura en el vaso. En el dibujo extendido se observa el abandono definitivo de la composición axial por el empleo de nuevos recursos como son los ejes inclinados y el movimiento para crear armonla y equilibrio plástico basado principalmente en el ritmo asimétrico de las formas.

El rostro del personaje nos muestra el perfil característico maya, en este caso singularizado por una decoración facial que consiste en dos gruesas líneas semicirculares y paralelas que corren de la parte media de la mejilla hasta el mentón. Parte de la abundante cabellera cae sobre los hombros, la otra se yergue airosa, a manera de penacho. De la parte media superior de la frente sale el tallo de una planta rematada por una hoja o flor que encierra dos bandas cruzadas en forma de $\mathbf{X}$, representación simbólica del cielo. El pelo, anudado graciosamente, y otros adornos complementan la decoración de la cabeza.

Crótalos de serpiente perfilan las piernas del personaje. El muslo derecho ostenta un tatuaje en forma de circulo, posible sfmbolo jeroglifico del día Cauac. La figura sostiene en la mano izquierda un hacha ceremonial de la que irradian hileras de pequeños circulitos; el mango se curva en el extremo inferior. Los accesorios ornamentales son los siguientes: orejera en forma de disco, decorada con el signo $I k$; collar de cascabeles del que pende un pectoral en forma de vasija invertida, decorada con el jeroglífico del día $\mathrm{Akbal}$, de la que emergen dos pequeñas serpientes. El cinturón, que sólo puede apreciarse parcialmente, parece realizado en un material suave, tela o madejas de algodón, y lo forman una sucesión de nudos de diferente tamaño y diseño, que rematan en el costado con una hermosa borla debajo, de la que pende, ondulante, la parte posterior del taparrabo, el elaborado remate anterior de éste, cuelga entre las dos piernas.

2 Proskouriakoff, 1950 , p. 138.

3 De la Fuente, 1965. p. 169. 
Es posible que esta hermosa figura juvenil sea la de un dios, cuya identidad es difícil aún probar ya que no presenta los rasgos iconográficos de los dioses mayas más conocidos y sus correspondientes jeroglificos nominales. Por lo pronto sólo puedo asentar que en este vaso aparece representado un personaje que por la vitalidad de sus movimientos pareciera emerger triunfante de la región del inframundo. El elemento serpentino en las piernas, Ia variedad de símbolos religioso que forman parte del atavío $y$, principalmente, el que la imagen se integre a una escena mitológica, parece confirmar la hipótesis de que se trata de un dios y no de un hombre.

La figura posee ciertas características que pudieran identificarlo, muy tentativamente, con el dios Chicchan, descrito por Schellhas como el dios $H$, deidad relacionada con la serpiente. Schellhas, discute, sin admitirlas, las hipótesis de Brinton y de Seler, quienes identificaron a Chicchan como una deidad joven. ${ }^{\star}$ Por otra parte, Anders en su reciente libro sobre el panteón maya describe al dios como un ser que posee características de hombre y de serpiente; según el autor son 4 los dioses Chicchan, cada uno rigiendo los puntos cardinales y considera al Chicchan, el del Norte, como la deidad principal. ${ }^{5} \mathrm{La}$ figura representada en la vasija es una deidad joven que coge con su mano derecha una máscara que tiene semejanza con el jeroglifico del dios $C$, deidad celeste que parece simbolizar a la estrella polar. ${ }^{6}$

Sin embargo, a pesar de lo asentado en párrafos anteriores, me parece que tiene un especial interés señalar las similitudes iconográficas que observo entre el "dios" antropomorfo del vaso y la figura central del tablero maya de Dumbarton Oaks, Washington. ${ }^{7}$ Beatriz de la Fuente opina que la figura central de este bello relieve de piedra es un noble señor palencano que forma parte de una escena cuyo tema es "indiscutiblemente de carácter simbólico religioso", ${ }^{8}$ ya que éste aparece representado no sólo como jefe político, sino también como sacerdote que ejecuta una ceremonia ritual.

Los elementos que relacionan a la figura del vaso con la del tablero de Dumbarton Oaks son los siguientes: el personaje palencano sostiene en la mano derecha una bolsa rígida decorada con el signo $\mathrm{Akbal}$ y de la que cuelga una viborilla; la bolsa es idéntica en diseño al pectoral que

4 Schellhas, 1904, p. 30.

5 Anders, 1969, p. 288.

6 Schellhas, 1904, p. 21.

7 Coe y Benson, 1966, pp. 16 a 20.

8 De la Fuente, 1968, pp. 37 a 40. 
adorna al dios joven del vaso; el hacha ceremonial que porta el dignatario palencano, el símbolo del cielo que tiene como adorno en el tocado, las borlas que rematan el elaborado cinturón, los cubre tobillos y puños, la forma como la mano izquierda sostiene el hacha ceremonial y el pie que sugiere un paso de danza, son elementos que poseen una impresionante similitud con los de la figura del vaso. El personaje histórico del tablero y el "dios" joven del vaso forman parte de escenas cuyo significado es religioso.

La interacción temática y de símbolos que observo entre ambas figuras no parece ser casual, sino que plantea problemas muy interesantes como son la localización del sitio maya del que procede el vaso y la posición cronológica de éste en relación con la del tablero, el que parece haber sido "ejecutado a principios del siglo vi11". ${ }^{8}$

En conclusión, varias son las posibles interpretaciones del contenido temático de la decoración del hermoso vaso maya, tema de estas reflexiones:

13 Se trata de la representación simbólica del triunfo de la vida sobre la muerte. El personaje joven serfa símbolo de la vida.

$2^{\text {E }}$ Es la representación de un mito cósmico en el que participan el sol diurno y el sol nocturno, la muerte y los seres fantásticos que habitan en el inframundo, en la región de las tinieblas. El personaje joven, en este caso, simbolizaría al sol diurno, sería imagen del día, cle la luz y de la región celeste.

Las dos interpretaciones anteriores no se excluyen entre sí, se complementan; puede afirmarse que surgen, de inmediato, al contemplar el diseño decorativo del vaso y reflexionar sobre su posible significación temática.

A continuación, propongo otras dos hipótesis, más sutiles, pero también más difíciles de comprobar. Una, es la que expresé en páginas anteriores al considerar al personaje joven del vaso como la representación de un dios, posiblemente el dios Chicchan que habita en los puntos cardinales.

La última hipótesis consiste en ver la figura joven del vaso como la imagen glorificada y divinizada del personaje histórico esculpido en cl relieve de piedra de Dumbarton Oaks. La inclusión de una figura de la vida real en un relato mítico, tal vez tenía el propósito de acen-

I Ibidem, p. 39. 
tuar el rango divino y la dignidad religiosa del gobernante o sacerdote de Palenque o de alguna ciudad circunvecina.

Si esta última hipótesis fuera válida podría afirmar que en el hermoso dibujo del vaso maya están contenidos el relato mítico y el registro histórico.

Todas las reflexiones anteriores no pueden aún convertirse en afirmaciones teóricas con validez científica. Por lo pronto, resultan estimulantes y sugerentes para proseguir en el estudio de la iconografía maya y valorar estéticamente las múltiples manifestaciones del arte maya; en este caso, la pintura en pequeño formato de un estupendo vaso del periodo clásico.

\section{BIBLIOGRAFIA}

\section{ANders, Ferdinand.}

1963 Das Pantheon der Maya. Akademische Druck und Verlaganstalt, Graz. Austria.

Coe, Michael D. y Elizabetil P. Benson.

1966 "Three Maya Reliefs at Dumbarton Oaks." Studics in Pre.Columbian Art and Archaeology. Number Two. Dumbarton Oaks. Trustess for Harvard University. Washington, D. C.

De la Fuente, Beatriz.

1968 "Un Relieve de Palenque en Washington." Anales del Instituto de Investigaciones Estéticas. Núm. 37. UNAM, México.

León-Portilla, Miguel.

1968 Tiempo y Realidad en el Pensamiento Maya. Ensayo de acercamiento. Instituto de Investigaciones Históricas. UNAM, México.

Proskouriakoff, Tatiana.

1950 A Study of Classic Maya Sculpture. Publ. 593 Carnegie Institution of Washington, Washington, D. C.

Schellhas, Paul.

1904 Representation of Deities of the Maya Manuscripts. Papers of The Peabody Museum of American Archaeology and Ethnology, Harvard University. Vol. IV, núm. I, 2nd. edition, revised. Cambridge, Mass.

Thompson, J. ERIC.

1962 Maya Hieroglyphic Writing. 2nd. printing. University of Oklahoma Press. Norman.

Tozzer M., Alfred y Glover M., Allen.

1910 "Animal Figures in the Maya Codices." Papers of the Peabody 
Museum of American Archaeology and Ethnology. Harvard University. Vol. IV, núm. 3. Cambridge, Mass.

\section{ZimMERMANN, GÜNTER.}

1956 Die Hieroglyphen der Maya-Handschriften. Universität, Hamburg. Cram, de Gruyter \& Cio. 